\title{
The biology of PCSK9 from the endoplasmic reticulum to lysosomes: new and emerging therapeutics to control low-density lipoprotein cholesterol
}

\author{
This article was published in the following Dove Press journal: \\ Drug Design, Development and Therapy \\ 3 October 2013 \\ Number of times this article has been viewed
}

\author{
Steve Poirier ${ }^{1,2}$ \\ Gaétan Mayer ${ }^{1-3}$ \\ 'Laboratory of Molecular Cell Biology, \\ Montreal Heart Institute, Montréal, \\ QC, Canada; ${ }^{2}$ Départements de \\ Pharmacologie, ${ }^{3}$ Médecine, Faculté de \\ Médecine, Université de Montréal, \\ Montréal, QC, Canada
}

\begin{abstract}
Proprotein convertase subtilisin/kexin type 9 (PCSK9) directly binds to the epidermal growth factor-like repeat A domain of low-density lipoprotein receptor and induces its degradation, thereby controlling circulating low-density lipoprotein cholesterol (LDL-C) concentration. Heterozygous loss-of-function mutations in PCSK9 can decrease the incidence of coronary heart disease by up to $88 \%$, owing to lifelong reduction of LDL-C. Moreover, two subjects with PCSK9 loss-of-function mutations on both alleles, resulting in a total absence of functional PCSK9, were found to have extremely low circulating LDL-C levels without other apparent abnormalities. Accordingly, PCSK9 could represent a safe and effective pharmacological target to increase clearance of LDL-C and to reduce the risk of coronary heart disease. Recent clinical trials using anti-PCSK9 monoclonal antibodies that block the PCSK9:low-density lipoprotein receptor interaction were shown to considerably reduce LDL-C levels by up to $65 \%$ when given alone and by up to $72 \%$ in patients already receiving statin therapy. In this review, we will discuss how major scientific breakthroughs in PCSK9 cell biology have led to the development of new and forthcoming LDL-C-lowering pharmacological agents.
\end{abstract}

Keywords: PCSK9, LDLR, LDL-cholesterol, lipoproteins, coronary heart disease, inhibitors, monoclonal antibody therapy

\section{Introduction}

The worldwide prevalence of cardiovascular diseases (CVDs) is a major public health problem that is expected to increase in the next decades. ${ }^{1,2}$ Elevated circulating lowdensity lipoprotein cholesterol (LDL-C) is one of the major risk factors positively correlated with premature development of CVD. ${ }^{3-5}$ Subendothelial retention of LDL particles within the arterial walls is an important initiating event in atherosclerosis, leading to pathological accumulation of lipids and cell debris and chronic inflammation, often culminating in coronary events and stroke. ${ }^{1,6}$ Through binding of apolipoprotein B100 (ApoB), plasma LDL particles are mainly cleared by hepatic LDL receptor (LDLR)-mediated endocytosis. ${ }^{7}$ Heterozygous familial hypercholesterolemia $(\mathrm{HeFH})$, characterized by elevated levels of circulating LDL-C, occurs in about one in 500 people who inherit genetic mutations mostly in $L D L R$ but also in $A P O B, A R H$, and APOE loci. ${ }^{8,9}$ In 2003, proprotein convertase subtilisin/kexin type 9 (PCSK9), ${ }^{10}$ which has been identified as the third locus associated with familial hypercholesterolemia (FH) (Figure 1), ${ }^{11,12}$ was shown to code for a natural inducer of LDLR degradation. ${ }^{13-15}$
Correspondence: Gaétan Mayer Laboratory of Molecular Cell Biology, Montreal Heart Institute Research Center, 5000 Bélanger Street, Room S-5350, Montréal, QC, Canada HITIC8

$\mathrm{Tel}+\mathrm{I} 5 \mathrm{I} 43763330$

Fax +15143761355

Email gaetan.mayer@icm-mhi.org 
$+\operatorname{PCSK9}(\mathrm{GOF})$
$\uparrow \mathrm{LDL}-\mathrm{C}$

- PCSK9 (LOF)

$\downarrow$ LDL-C

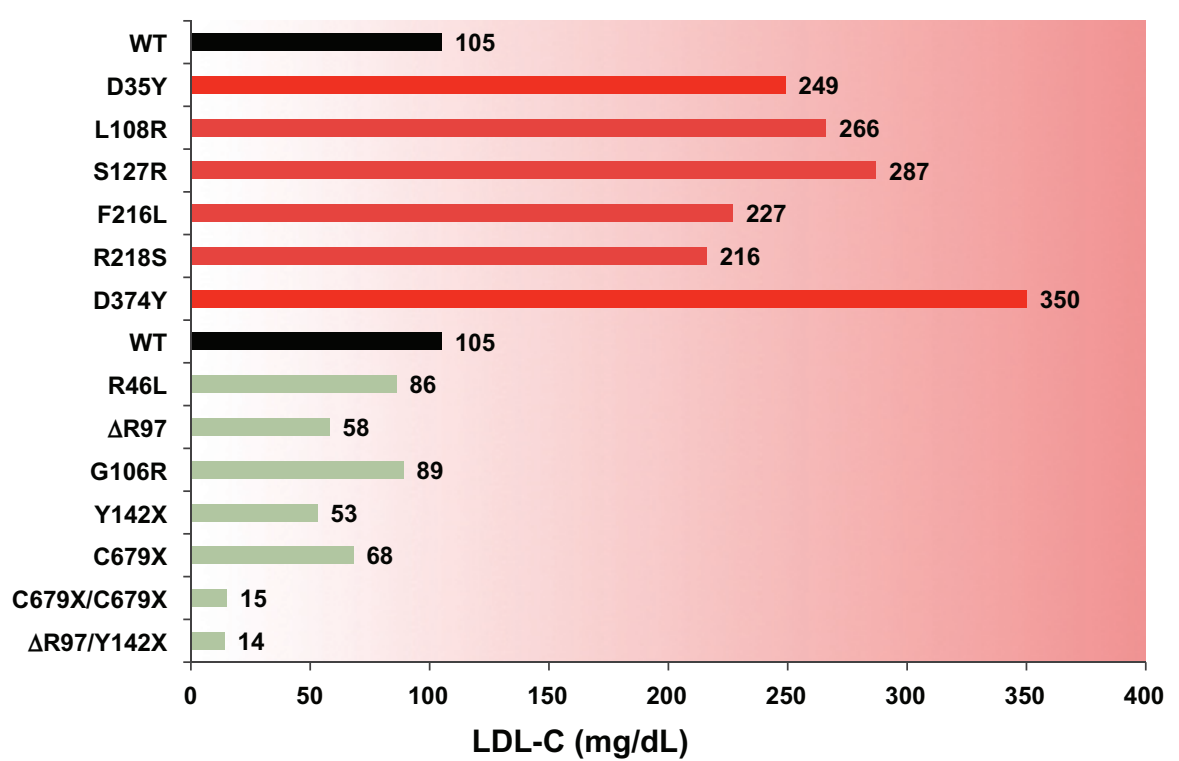

\begin{tabular}{|lcccl|}
\hline Exons & Mutations & TC $\mathbf{( m g / d L )}$ & LDL-C $\mathbf{( m g / d L})$ & Reference \\
\hline E1/E3 & $\Delta$ R97/Y142X & - & 14 & Zhao et al $^{17}$ \\
E12 & C679X/C679X & 85 & 15 & Hooper et al ${ }^{18}$ \\
E12 & C679X & $150 \pm 25$ & $68 \pm 27$ & Cohen et al $^{16}$ \\
E3 & Y142X & $145 \pm 24$ & $53 \pm 40$ & Cohen et al $^{16}$ \\
E2 & G106R & 119 & 89 & Berge et al $^{17}$ \\
E1 & RR97 & - & 58 & Zhao et al $^{37}$ \\
E1 & R46L & $134 \pm 15$ & $86 \pm 20$ & Berge et al $^{17}$ \\
& WT & $178 \pm 41$ & $105 \pm 37$ & Cohen et al $^{16}$ \\
E7 & D374Y & $416 \pm 96$ & $350 \pm 97$ & Leren $^{77}$ \\
E4 & R218S & $328 \pm 57$ & $216 \pm 48$ & Allard et al $^{51}$ \\
E4 & F216L & $299 \pm 123$ & $227 \pm 112$ & Abifadel et al $^{11}$ \\
E2 & S127R & $363 \pm 68$ & $287 \pm 72$ & Abifadel et al $^{11}$ \\
E2 & L108R & $337 \pm 53$ & $266 \pm 53$ & Abifadel et al $^{12}$ \\
E1 & D35Y & $307 \pm 10$ & $249 \pm 19$ & Abifadel et al $^{12}$ \\
\hline
\end{tabular}

Figure I Effect of proprotein convertase subtilisin/kexin type 9 (PCSK9) human mutations on plasma low-density lipoprotein cholesterol (LDL-C) levels. Selected PCSK9 gainof-function (GOF, red) and loss-of-function (LOF; green) mutations and their impact on circulating LDL-C and total cholesterol (TC; lower panel) are shown. Subjects with wild-type alleles (WT) are used as a reference. An exhaustive list of PCSK9 mutations can be found at http://www.ucl.ac.uk/ldlr/Current/.

Loss-of-function ${ }^{16-18}$ (LOF) mutations or genetic invalidation $^{19}$ at the PCSK9 locus robustly lower circulating LDL-C (Figure 1) and reduce cardiovascular events by up to $\sim 88 \%$ in humans. ${ }^{20}$ So far, $>1,700 L D L R$ and $>160$ PCSK9 allelic variants have been identified. ${ }^{21-23}$ Based on human genetic studies, PCSK9 inhibition should represent a new potent approach to lower LDL-C with the aim to reduce progression of atherosclerosis and CVD risk.

\section{Regulation of PCSK9 gene expression}

In adult mice, $P C S K 9$ is almost exclusively expressed in the liver and to a lesser extent in other tissues such as the intestine and kidney. ${ }^{10}$ In functional genomics studies, PCSK9 has been identified as a direct sterol regulatory elementbinding protein-2 (SREBP-2) target coregulated with the rate-limiting enzyme for cholesterol synthesis 3-hydroxy- 3-methylglutaryl coenzyme A (HMG-CoA) reductase and $L D L R .^{24,25}$ This regulation is of importance, given that statins (HMG-CoA reductase inhibitors), the most important class of LDL-lowering drugs currently used in the clinic, ${ }^{26}$ also increase the expression of PCSK $9,{ }^{27}$ which significantly attenuates their potency at increasing LDLR levels. ${ }^{19}$ This mechanism could explain why for many patients at high risk for CVD, LDL-C levels are not reaching the therapeutic goals with statin therapy alone. Expression of PCSK9 is also regulated by the bile acid-regulated hepatocyte nuclear factor 1 (HNF1), ${ }^{28}$ which is crucial for the full transcriptional activity of SREBP-2 at the PCSK 9 promoter. ${ }^{29}$ The lipid-lowering compound berberine, ${ }^{30}$ which is an alkaloid isolated from a Chinese herb used in traditional medicine, was shown to strongly lower PCSK 9 gene expression by reducing $H N F 1 \alpha$ mRNA levels. ${ }^{29,31}$ In addition, berberine also increases LDLR mRNA stability, ${ }^{32}$ and based on these properties it 
has been proposed that it could be used as a monotherapy or in combination with statins to treat hypercholesterolemic patients. ${ }^{30,31}$

\section{Autocatalytic activation and PCSK9 exit from the endoplasmic reticulum}

Human PCSK9 encodes a 692 amino acid protein composed of a signal peptide (aa 1-30), a prosegment (aa 31-152), a catalytic domain (aa 153-404), a hinge region (HR; aa 405-454), and a C-terminal cysteine- and histidine-rich domain (CHRD; aa 455-692; Figure 2A). ${ }^{10,33}$ The newly synthesized $\sim 72 \mathrm{kDa}$ proPCSK 9 is translocated in the endoplasmic reticulum (ER) and undergoes autocatalytic processing of its prosegment at the $\mathrm{VFAQ}_{152} \downarrow$ SIP site. ${ }^{34}$ Crystallographic studies confirmed that mature PCSK9 has three distinct domains with the prosegment noncovalently bound to the catalytic domain and the CHRD, resulting in a triangular pyramid shape (Figure $2 \mathrm{~B}$ ) ${ }^{33}$ Similar to other proprotein convertases, ${ }^{35,36}$ the cleaved prosegment is an inhibitor and an intramolecular chaperone of the catalytic domain required for proper folding and ER exit of PCSK9. ${ }^{10}$ Indeed, LOF mutations in the prosegment can result in lower circulating PCSK9 due to impaired autocatalytic processing and secretion. ${ }^{37}$ Moreover, misfolded precursors in the ER act in a dominant negative manner by strongly decreasing secretion of PCSK9 from the wild-type allele. ${ }^{38,39}$ Therefore, it is considered that inhibition of PCSK9 autoactivation would be a suitable approach to lower LDL-C. However, the exact mechanism by which PCSK9 exits the ER remains largely unknown. A recent study identified the COPII-coated vesicle component $\operatorname{Sec} 24 \mathrm{~A}^{40}$ as a selective cytosolic factor for vesicular packaging and ER-to-Golgi trafficking of PCSK9 (Figure 3). ${ }^{41} \operatorname{Sec} 24 \mathrm{~A}$ deficiency was shown to significantly lower circulating PCSK9 and LDL-C in mice. Selective ER export of soluble PCSK9 would involve its binding to a transmembrane cargo receptor that interacts with Sec24A through its cytosolic tail, thereby initiating packaging into COPII
A

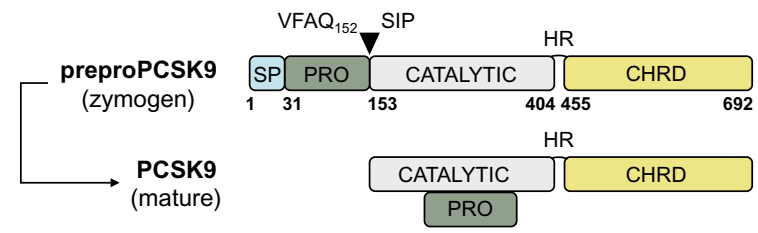

B

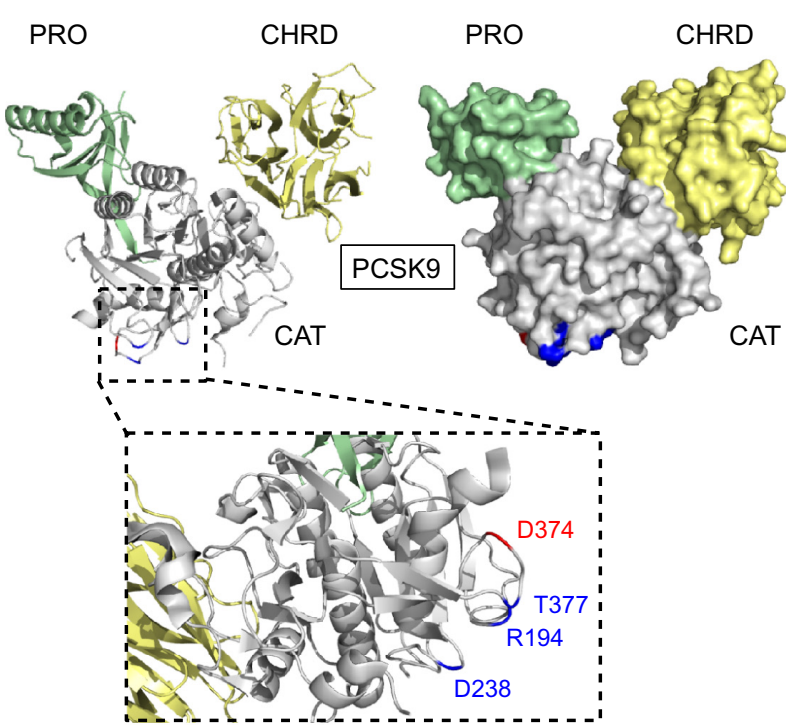

C

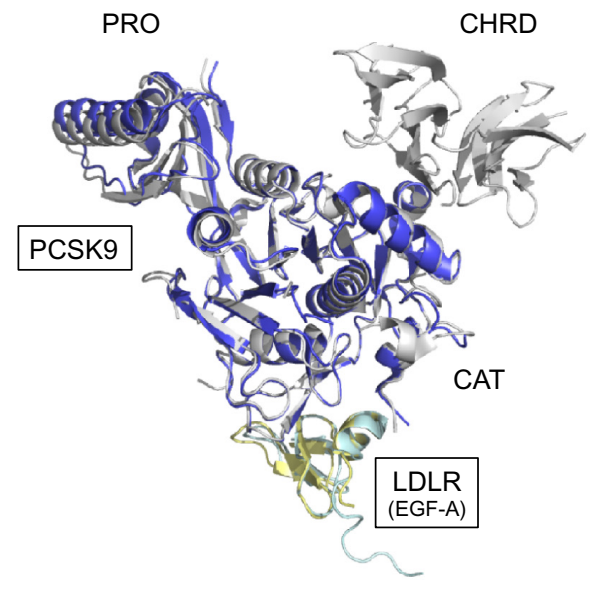

PCSK9-V5

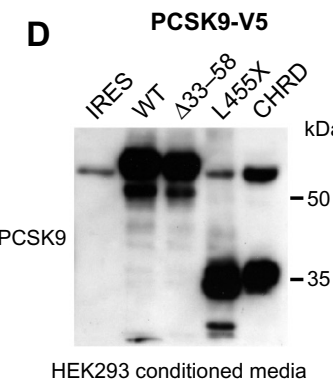

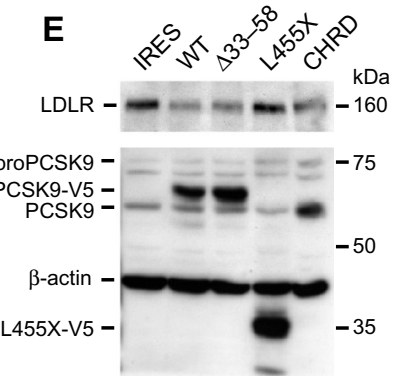

Figure 2 Proprotein convertase subtilisin/kexin type 9 (PCSK9) structure and importance of the cysteine- and histidine-rich domain (CHRD) in low-density lipoprotein receptor (LDLR) degradation. (A) After removal of the signal peptide (SP; aa I-30, light blue), human proPCSK9 is autocatalytically cleaved at position Q I52 within the endoplasmic reticulum, resulting in mature PCSK9 comprising the prosegment (PRO; aa 3I-I52, green), catalytic domain (aa I53-404, gray), hinge region (HR; aa 405-454), and a C-terminal CHRD (aa 455-692, yellow). (B) Crystal structure of PCSK9 was visualized using MacPymol (Protein Data Bank ID code PDB 2P4E). ${ }^{33}$ PCSK9 residues (R194, D238, T377, and D374) interacting with LDLR are emphasized (inset). ${ }^{55}$ PCSK9 residue D374, highlighted in red, is the site of D374Y gain-of-function (GOF) mutation causing severe hypercholesterolemia. ${ }^{76,77}$ (C) Superposition of PCSK9:epidermal growth factor-like repeat A (EGF-A) complexes with (gray:yellow; PDB 3BPS) ${ }^{55}$ or without PCSK9-CHRD domain (blue:light blue; PDB 2W2M). ${ }^{69}$ (D) Western blot of media from HEK293 cells transfected with an empty internal ribosome entry site expression vector (IRES) or with plasmids encoding full-length (WT) or truncated human V5-tagged PCSK9 constructs (deltaPRO, $\Delta 33-58$; deltaCHRD, L455X, or CHRD alone).$^{74}$ (E) HepG2 cells were incubated with HEK293-derived conditioned media (shown in [D]), and LDLR, PCSK9, and $\beta$-actin protein levels were analyzed by Western blotting. 


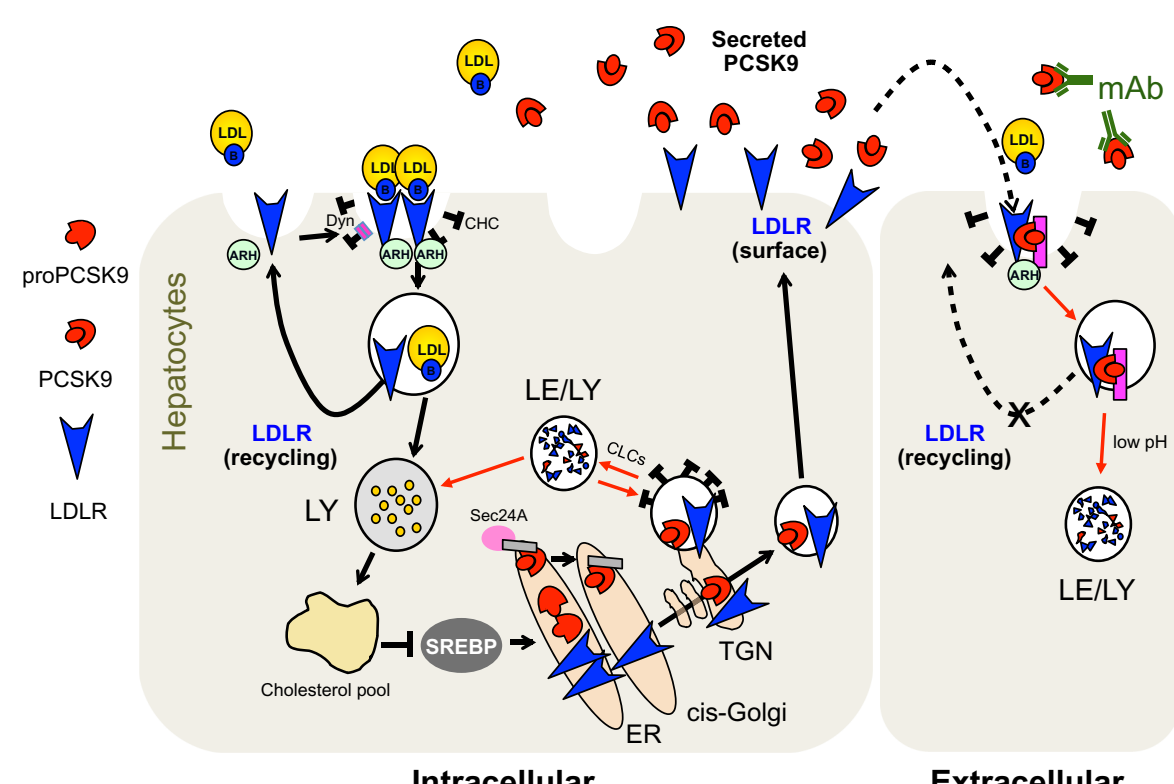

Figure 3 Current cellular model for PCSK9-assisted LDLR degradation. The pink rectangle at the cell surface and in endosomes denotes a putative PCSK9 cofactor needed for LDLR degradation. The gray rectangle in the ER denotes a putative ER cargo receptor.

Abbreviations: ARH, autosomal recessive hypercholesterolemia; B, apolipoprotein BI00; CHC, clathrin heavy chain; CLCs, clathrin light chains; Dyn, dynamin; ER, endoplasmic reticulum; LDL, low-density lipoprotein; LDLR, low-density lipoprotein receptor; LE, late endosomes; LY, lysosomes; mAb, monoclonal antibodies; PCSK9, proprotein convertase subtilisin/kexin 9; SREBP, sterol regulatory element-binding protein; TGN, trans-Golgi network.

vesicles and transport to the Golgi apparatus. Thus, Sec24A and the putative cargo receptor may also represent interesting targets to reduce circulating LDL-C.

Unlike other convertases, the N-terminal prosegment of PCSK9 is not released after a second autocatalytic cleavage but remains tightly associated with the catalytic domain, rendering PCSK9 enzymatically inactive. ${ }^{33,42}$ In hepatocytes, PCSK9 is also prone to proteolytic cleavage by proprotein convertases, which can be localized in the Golgi, endosomes, and at the plasma membrane. ${ }^{43-46}$ Studies demonstrated that furin cleaves PCSK9 at position R218, generating a truncated form with lower affinity to LDLR. ${ }^{47-50}$ Human PCSK9 gain-of-function (GOF) mutations R218S ${ }^{51}$ and F216 $\mathrm{L}^{11}$ associated with severe hypercholesterolemia (Figure 1) presumably lead to an increased pool of "active" PCSK9 by preventing the cleavage by furin. However, furin-cleaved PCSK9 may still be active, as it was found to bind LDLR and to reduce its levels in vitro and in vivo. ${ }^{50}$ Interestingly, although R218 is not in direct contact with the epidermal growth factor-like repeat A (EGF-A) domain, PCSK9-R218A mutation showed a ten-fold weaker binding to LDLR ${ }^{52}$ This finding suggests that R218 is involved in intramolecular PCSK9 interactions or binds to other LDLR residues.

\section{PCSK9 targets LDLR towards lysosomes for degradation}

PCSK9 induces intracellular degradation of LDLR in acidic compartments $^{53}$ independently of its catalytic activity, ${ }^{42}$ thereby causing LDL-C levels to rise. ${ }^{13-15,19}$ So far, the exact mechanism by which PCSK9 induces LDLR degradation remains elusive. The prevailing hypothesis is that PCSK9 directly interacts with the EGF-A domain of LDLR (Figure 4A), ${ }^{54,55}$ forming a complex that is internalized in endosomes via clathrin-coated pits and the cytosolic adaptor protein ARH (Figure 3) ${ }^{56-58}$ Interestingly, the EGF-A domain is not directly involved in apolipoprotein binding but rather is important for their release in endosomes. ${ }^{59}$ In the acidic environment of endosomes, the affinity of PCSK9 for the LDLR increases considerably (Figure 4B), ${ }^{33}$ which might create additional sites of interaction. ${ }^{60}$ This two-step binding model would explain how PCSK9 hinders recycling of LDLR to the cell surface, ${ }^{61}$ thereby promoting its degradation by lysosomal hydrolases independently of ubiquitination, autophagy, and the endosomal sorting complex. ${ }^{57}$ Based on a study showing that PCSK9 can degrade the LDLR in the absence of ARH, ${ }^{15}$ an intracellular pathway of LDLR degradation was also demonstrated (Figure 3). Indeed, clathrin light chains small interfering RNAs (siRNA), which block intracellular trafficking from the trans-Golgi network to lysosomes, rapidly prevented LDLR degradation in human liver-derived HepG2 cells in a PCSK9-dependent fashion without affecting the ability of exogenous PCSK9 to enhance LDLR degradation. ${ }^{62}$

Although PCSK9 primarily interacts with LDLR via its catalytic domain (Figure 4A), ${ }^{55}$ over $60 \%$ of human 

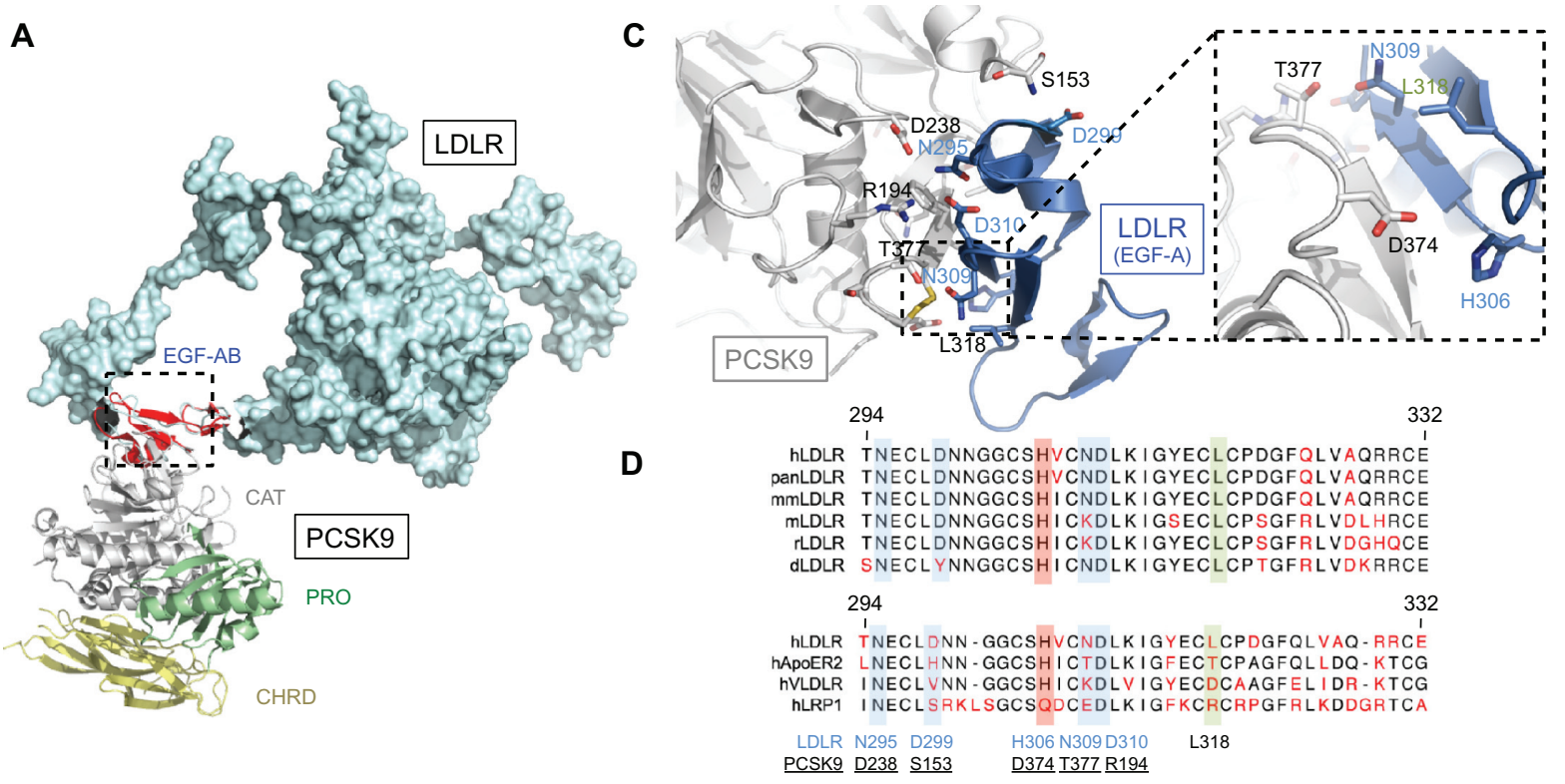

\begin{tabular}{|c|c|c|c|}
\hline PCSK9:LDLR-ECD $\left(K_{D}=\mathrm{nM}\right)$ & $\mathrm{pH} 7.5$ & $\mathrm{pH} 5.4$ & Cunningham et $\mathrm{a}^{33}$ \\
\hline WT & $169 \pm 13$ & $1.0 \pm 0.47$ & Direct binding of PCSK9 and its natural mutants to LDLR-ECD \\
\hline F216L & $207 \pm 21$ & $\begin{array}{c}42 \pm 14 \\
0.8 \pm 0.03\end{array}$ & \\
\hline & & $50 \pm 10$ & \\
\hline S127R & $32 \pm 8$ & $0.8 \pm 0.10$ & \\
\hline & $86 \pm 23$ & $56 \pm 10$ & \\
\hline $\mathrm{D} 374 \mathrm{Y}$ & $6 \pm 1$ & $1.6 \pm 0.12$ & \\
\hline PCSK9:EGF-AB (EC $\left.{ }_{50}=\mathrm{nM}\right)$ & & & McNutt et al $7^{9}$ \\
\hline WT:LDLR-WT & 497.6 & & Direct binding of PCSK9 to LDLR (EGF-AB; WT vs H306Y) \\
\hline WT:LDLR-H306Y & 195.6 & & \\
\hline PCSK9:ECD $\left(\mathrm{EC}_{50}=\mathrm{nM}\right)$ & & & Shan et al $\left.\right|^{80}$ \\
\hline WT:LDLR & 0.3 & & Direct binding of PCSK9 to LDLR, VLDLR, ApoER2-ECDs \\
\hline WT:VLDLR & 3.0 & & \\
\hline WT:ApoER2 & 28.2 & & \\
\hline PCSK9:ECD $\left(K_{0}=n M\right)$ & & & Liu et a $\left.\right|^{81}$ \\
\hline WT:LDLR & 386 & & Direct binding of PCSK9 to LDLR, VLDLR, ApoER2-ECDs \\
\hline WT:VLDLR & 379 & & \\
\hline WT:ApoER2 & 516 & & \\
\hline
\end{tabular}

Figure 4 PCSK9:LDLR binding interface and comparative analysis with other LDLR family members. (A) Structure of PCSK9:EGF-AB (PDB 3BPS) ${ }^{55}$ complex superposed to LDLR ECD (PDB IN7D) ${ }^{131}$ was determined using MacPymol. (B) Residues mainly involved in PCSK9 (gray) and LDLR (EGF-A, blue) binding are represented: SI53:D299, D238:N295, R194:D310, T377:N309, and L318. Critical interacting residues PCSK9-D374 and LDLR-H306 implicated in PCSK9-D374Y and LDLR-H306Y GOF mutations are emphasized (inset). ${ }^{79}$ (C) Primary sequence alignments of LDLR-EGF-A domain from selected species and human LDLR family members (ApoER2, VLDLR, and LRPI) were performed using the CLC Workbench. Of note is the high sequence homology between EGF-A domains and PCSK9 interacting residues. (D) Binding affinity of PCSK9 to LDLR family members at neutral or acidic $\mathrm{pH}$.

Abbreviations: d, Danio rerio; ECD, extracellular domain; EGF, epidermal growth factor; GOF, gain-of-function; h, Homo sapiens; LDLR, low-density lipoprotein receptor; m, Mus musculus; mm, Macaca mulatta; pan, Pan troglodytes; PCSK9, proprotein convertase subtilisin/kexin 9; PDB, Protein Data Bank; r, Rattus norvegicus, VLDLR, very lowdensity lipoprotein receptor; WT, wild-type; $K_{D}$, dissociation constant; $E_{50}$, half maximal effective concentration.

mutations in PCSK9 are localized in the prosegment $(\sim 34 \%)$ or the HR-CHRD $(\sim 29 \%))^{22}$ Intriguingly, it was shown that removal of the prosegment $\mathrm{N}$-terminal acidic stretch (aa 31-53) results in increased PCSK9 binding to LDLR by $\sim$ ten-fold, ${ }^{55}$ in a four-fold increased activity on LDLR degradation and faster endocytosis in lysosomes-like compartments. ${ }^{63,64}$ It was recently proposed that LDL particles, possibly through their ApoB molecule, ${ }^{65}$ interact with the N-terminal acidic stretch of PCSK9 and, by an allosteric mechanism, inhibit its binding to LDLR and depress its degradation. ${ }^{66,67}$ The crystal structure of LDLR bound to PCSK9 at neutral $\mathrm{pH}$ revealed a low-affinity interaction between residue L108 of the prosegment and residue L626 of the LDLR $\beta$-propeller that seemed to stabilize the receptor in an extended conformation. ${ }^{68}$ On the other hand, although PCSK9- $\triangle$ C (lacking its CHRD) cocrystallizes with EGF-A (Figure 2C), ${ }^{69}$ it is unable to direct the PCSK9:LDLR complex for lysosomal degradation (Figure 2D and E). ${ }^{61}$ Recent in vitro studies showed that the CHRD could interact with (1) the ligand-binding domain of LDLR, allowing PCSK9 to remain bound to the receptor at low $\mathrm{pH},{ }^{60,70}$ and (2) its own prosegment in an intramolecular interaction that could regulate PCSK9 secretion and function. ${ }^{71}$ Importantly, it was found that a PCSK9 C-terminal domain antibody, which does not affect the PCSK9:LDLR interaction, inhibited PCSK9 internalization and LDLR degradation, revealing the importance of the CHRD for the cellular uptake of PCSK9. ${ }^{72}$ In addition, it was reported that the cytosolic tail of LDLR 
is not required for its PCSK9-dependent degradation. ${ }^{73}$ This suggests that a putative transmembrane protein would bind the CHRD and connect PCSK9 to cytosolic adaptors in order to sort the PCSK9:LDLR complex to lysosomes (Figure 3). This is in agreement with the C-terminal domain being solvent-exposed, enabling cofactor binding. ${ }^{68}$ Annexin A2 (AnxA2) was found to bind the $\mathrm{CHRD},{ }^{74}$ but in wild-type mice the almost complete absence of $A n x A 2$ expression in liver precludes it from being required for PCSK 9 activity in hepatocytes. ${ }^{75}$ However, analyses of $A n x A 2^{-/-}$mice revealed an increase in circulating PCSK9 and in LDL-C and a decrease of LDLR levels in extrahepatic tissues. ${ }^{75}$ A 73-aa peptide derived from AnxA2 R1 domain (aa 25-97) inhibited PCSK9 binding to LDLR with a half maximal inhibitory concentration $\left(\mathrm{IC}_{50}\right)$ of $0.6 \mu \mathrm{M}$ (Table 1). Moreover, AnxA2 prevented PCSK9-induced LDLR degradation in hepatic cell lines and in vivo in mice livers following ectopic overexpression. ${ }^{75}$ Therefore, peptides derived from AnxA2 or synthetic peptidomimetic derivatives are attractive strategies to inhibit PCSK9.

\section{Direct interaction of PCSK9 to LDLR}

At neutral pH, PCSK9 associates to LDLR with a $K_{\mathrm{D}}$ of $\sim 169 \mathrm{nM}$ (Figure 4B). ${ }^{33}$ At endosomal acidic $\mathrm{pH}$, PCSK9 binding to LDLR is increased by 150-170-fold $\left(K_{\mathrm{D}} \sim 1 \mathrm{nM}\right)^{33,66}$ and in vitro data also revealed another form of PCSK 9 having a $K_{\mathrm{D}}$ of $42 \mathrm{nM}$ (Figure 4B), ${ }^{33}$ possibly due

Table I Peptidomimetic inhibition of PCSK9

\begin{tabular}{|c|c|c|}
\hline Inhibitor assay & $\mathbf{I C}_{50}=\mu \mathbf{M}$ & Reference \\
\hline PCSK9:LDLR & & Shan et al ${ }^{80}$ \\
\hline EGF-A (LDLR) & 3.4 & $\begin{array}{l}\text { Competitive inhibition of } \\
\text { PCSK9:LDLR }\end{array}$ \\
\hline PCSK9:VLDLR & & Shan et $a^{80}$ \\
\hline EGF-A (LDLR) & 4.7 & $\begin{array}{l}\text { Competitive inhibition of } \\
\text { PCSK9:VLDLR }\end{array}$ \\
\hline PCSK9 vs Dil-LDL & & Poirier et al ${ }^{62}$ \\
\hline EGF-A (LDLR) & 2 & $\begin{array}{l}\text { Dil-LDL uptake by addition of } \\
\text { EGF-A peptide }\end{array}$ \\
\hline PCSK9:LDLR & & Zhang et $\mathrm{al}^{82}$ \\
\hline EGF-A (LDLR) & $>6$ & $\begin{array}{l}\text { Competitive inhibition of } \\
\text { PCSK9:LDLR binding }\end{array}$ \\
\hline EGF-A variant 66 & 0.003 & \\
\hline PCSK9:LDLR & & Seidah et $\mathrm{al}^{75}$ \\
\hline RI domain (AnxA2) & 0.6 & $\begin{array}{l}\text { Noncompetitive inhibition of } \\
\text { PCSK9:LDLR-ECD by addition } \\
\text { of the RI domain of AnxA2 }\end{array}$ \\
\hline
\end{tabular}

Abbreviations: AnxA2, annexin A2; ECD, extracellular domain; EGF-A, epidermal growth factor-like repeat $A ; I_{50}$, half maximal inhibitory concentration; LDLR, low-density lipoprotein receptor; PCSK9, proprotein convertase subtilisin/kexin type 9; VLDLR, very low-density lipoprotein receptor; Dil-LDL, I, I'-dioctadecyl$3,3,3^{\prime}, 3^{\prime}$-tetramethyl-indocarbocyanine low-density lipoprotein. to a second processing event in PCSK9. ${ }^{63}$ PCSK9-D374Y GOF mutation ${ }^{76,77}$ has a much greater affinity for the LDLR extracellular domain (Figure 4B) ${ }^{58}$ and leads to an extremely severe familial hypercholesterolemia phenotype. ${ }^{78}$ PCSK9D374 forms a salt bridge with the LDLR EGF-A-H306 residue, and the mutation $\mathrm{D} 374 \mathrm{Y}$ results in a more favorable distance, increasing the affinity for LDLR by $\sim 25$-fold at neutral $\mathrm{pH}$ and its LDLR degrading activity by $\sim$ ten-fold. ${ }^{33,58,66}$ In counterpart, the FH mutation LDLR-H306Y was also shown to increase binding affinity to PCSK9 by $\sim 2.5$-fold (Figure 4B). ${ }^{79}$ Thus, interacting residues PCSK9-D374 and LDLR-H306 act as a pH switch important to further weld complex formation to be subsequently degraded by lysosomal hydrolases..$^{53,69,79}$

The crystal structure of PCSK9 in complex with the EGF-A domain revealed that the binding site resides on the surface of PCSK9's catalytic domain but at more than $20 \AA$ away from the catalytic site (Figure 4A). ${ }^{55}$ Autocatalysis at position Q152 releases a newly available amine group $\left(-\mathrm{NH}_{2}\right)$ at a distance of $27 \AA$, forming a hydrogen bond with D299 of the LDLR (Figure 4C). ${ }^{55}$ Other residues directly involved in the avidity of PCSK9:LDLR interface are R194:D310, D238:N295, D374:H306, and T377:N309 (Figure 4C and D). ${ }^{55}$ Remarkably, it was shown that PCSK9 binds similarly to other LDLR family members (very LDLR [VLDLR] and ApoER2; Figure 4B) ${ }^{80}$ and that EGF-A peptides antagonize PCSK9 binding to LDLR and VLDLR (Figure 4B and Table 1). ${ }^{79-81}$ Although EGF-A is a relatively weak antagonist, a phage-display approach has revealed peptidic combinations with greatly improved affinity to PCSK9 (Table 1). ${ }^{82}$ These pioneering studies have clearly demonstrated that targeting the PCSK9:LDLR surface of interaction is a valuable therapeutic strategy to increase cell surface LDLR expression. However, orally active small-molecule inhibitors that would disrupt this interaction or interfere with the autocatalytic processing of PCSK9 in the ER have not yet been reported, possibly due to cytotoxicity and/or less than optimal potency and stability. ${ }^{36}$

\section{Monoclonal therapy to PCSK9}

Several clinical trials have shown a positive correlation between greater levels of LDL-C lowering and greater reductions in coronary heart disease risk. ${ }^{83,84}$ Statins, currently the most powerful class of lipid-lowering drugs, can help decrease LDL-C levels by $20 \%-55 \%$, depending on the statin molecule and dosage. ${ }^{85}$ In addition, combination of statins with ezetimibe, bile-acid sequestrants, or niacin produces 
an additional $10 \%-20 \%$ decrease in LDL-C. ${ }^{86}$ However, even if these therapies can help achieve strong reductions in LDL-C, more efficient LDL-C-lowering therapies are still needed, especially for patients with very high initial LDL-C levels. Many of these patients (10\%-20\%) have undesirable side effects with high-dose statins and/or fail to achieve recommended LDL-C targets. ${ }^{87}$ In order to fill these important clinical needs, monoclonal antibodies against PCSK9, which inhibit its binding to LDLR and mimic the effect of LOF mutations, are presently being tested in Phase II and III clinical trials.

\section{Pharmacokinetic and pharmacodynamic data Preclinical studies}

Studies using antibodies that disrupt the interaction between PCSK9 and LDLR and inhibit the PCSK9-mediated LDLR degradation have first been performed in cell culture systems ${ }^{88}$ and in vivo in mice and nonhuman primates. ${ }^{89}$ It has been reported that PCSK9 binding to LDLR can be blocked by $>80 \%$ using anti-PCSK 9 polyclonal antibodies. ${ }^{88}$ Amgen Inc (Thousand Oaks, CA, USA) developed a humanized anti-PCSK9 monoclonal antibody (mAb1) that blocked the PCSK9:LDLR interaction with an $\mathrm{IC}_{50}$ of $2.08 \pm 1.21 \mathrm{nM}$ and prevented LDLR degradation in HepG2 cells and in vivo in mice and nonhuman primates. ${ }^{89}$ In cynomolgus monkeys, a single $3 \mathrm{mg} / \mathrm{kg}$ intravenous injection of $\mathrm{mAbl}$ reduced circulating LDL-C by $80 \%$. Pharmacokinetic data demonstrated that circulating $\mathrm{mAb} 1$ had a half-life of $61 \pm 9$ hours. Notably, within 15 minutes and up to 3 days after mAb1 administration, more than $97 \%$ of free circulating PCSK 9 was complexed with the antibody. These positive preclinical data prompted a Phase I clinical trial to evaluate the safety and tolerability of multiple doses of mAb1 (now named AMG145) when given as an add-on to stable statin therapy in subjects with hyperlipidemia.

Merck Research Laboratories (Whitehouse Station, NJ, USA) developed a neutralizing anti-PCSK9 monoclonal antibody (1D05-IgG2) that structurally mimics the LDLR EGF-A domain..$^{90} 1 \mathrm{D} 05$ disrupted the PCSK9:LDLR interaction with an $\mathrm{IC}_{50}$ of $3.7 \pm 0.1 \mathrm{nM},{ }^{90}$ inhibited PCSK9 internalization, and completely restored LDL-C uptake in cells treated with wild-type PCSK 9 or GOF mutants. ${ }^{91}$ In in vivo experiments, one single intravenous injection of 1D05 reduced plasma LDL-C by $40 \%$ in a humanized transgenic mouse model (CETP/LDLr-hemi) and by up to $50 \%$ in healthy rhesus monkeys. This effect could be maintained for over 2 weeks, even though the antibody displayed a relatively short half-life of 3.2 days. Researchers at Merck reported the use of a similar antibody named 1B20, which blocks PCSK9 uptake in human primary hepatocytes and inhibits PCSK9:LDLR interaction with a calculated $\mathrm{IC}_{50}$ of $11.4 \pm 1.5 \mathrm{nM} .{ }^{92}$ Intravenous injections of $1 \mathrm{~B} 20$ reduced LDL-C by $50 \%-70 \%$ in CETP/LDLr-hemi mice and in healthy rhesus monkeys (half-life of 1B20 was 39 hours). Importantly, this study demonstrated that subcutaneous administration of 1B20 in rhesus monkeys robustly lowered LDL-C by up to $\sim 70 \%$, and LDL-C reduction lasted longer, returning to baseline levels after $\sim 28$ days compared with $\sim 12$ days for the intravenously injected antibody. Moreover, this study showed that dyslipidemic monkeys treated with a combination of 1B20 and simvastatin additively reduced LDL-C levels.

Pfizer-Rinat (New York, NY, USA) has reported a humanized monoclonal antibody directed against PCSK9. The J16 antibody binds to a three-dimensional epitope mapping to the catalytic domain of PCSK9 and also, in part, to the C-terminus of the prosegment. ${ }^{93}$ The antibody completely disrupts PCSK9:LDLR interaction ( $\left.\mathrm{IC}_{50} 1.4 \mathrm{nM}\right)$. When injected intravenously in cynomolgus monkeys, J16 (one $3 \mathrm{mg} / \mathrm{kg}$ dose, half-life of 2.3 days ${ }^{94}$ reduced LDL-C levels by $70 \%$, an effect that was maintained for 10 days. Similar results were observed when the antibody was administered to monkeys fed a high-fat diet (64\% reduction in LDL-C at the $3 \mathrm{mg} / \mathrm{kg}$ dose). In addition, when hypercholesterolemic monkeys receiving $50 \mathrm{mg} / \mathrm{kg} /$ day simvastatin, which reduced LDL-C by $43 \%$, were injected with a single dose of J16 at $3 \mathrm{mg} / \mathrm{kg}$, LDL-C levels were reduced by an additional 65\%, emphasizing the beneficial effect of an anti-PCSK9 antibody/ statin combination therapy. However, as for mAb1 and 1D05, J16 was reported to have a short half-life ( $\sim 2.3$ days). It was shown that $\mathrm{J} 16$ exhibits a dose-dependent half-life that is PCSK9 dependent. ${ }^{94}$ Opposite to mAb1 and 1D05, which inhibit the endocytosis of PCSK9, J16 is internalized in complex with PCSK9 and is degraded in lysosomes by a target-mediated clearance pathway, which usually occurs for antibodies targeting membrane-bound receptors. To enhance its pharmacokinetic and pharmacodynamic properties, J16 was modified to bind PCSK9 in a pH-sensitive manner by introducing histidines into complementarity determining regions. ${ }^{94}$ The resultant $\mathrm{J} 17$ antibody escapes degradation by dissociating from PCSK9 at acidic $\mathrm{pH}$ in endosomes and is recycled to the cell surface by neonatal Fc receptors. J17 was found to reduce LDL-C levels as well as the J16 antibody, but its effect lasted for two to three times as long, due to its prolonged half-life, in mice (12.9 days; $1 \mathrm{mg} / \mathrm{kg}$ ) and monkeys ( 7.4 days; $1.5 \mathrm{mg} / \mathrm{kg}$ ). 
Eli Lilly (Indianapolis, IN, USA) recently developed a monoclonal antibody against PCSK9 catalytic domain (aa 160-181 $)^{95}$ that inhibits PCSK9 binding to LDLR and its degradation in HepG2 cells with an $\mathrm{IC}_{50}$ of $104 \mathrm{nM}$. Following a single intravenous or subcutaneous dose of $5 \mathrm{mg} / \mathrm{kg}$ in healthy cynomolgus monkeys, half-life serum concentration of the antibody was 7.3 days and 5.4 days, respectively. A maximal LDL-C decrease of $60 \%$ was observed, and LDL-C reduction was maintained below that of baseline levels for approximately 8 weeks. When administered subcutaneously, this antibody was as effective in reducing LDL-C levels as that observed after intravenous injection. ${ }^{95}$

\section{Human clinical studies}

Recent results from Phase I and II clinical trials represent a major step in the quest to develop new and potent lipidlowering therapy based on PCSK9-neutralizing antibodies. The first-in-human Phase I studies were conducted by Regeneron Pharmaceuticals, Inc (Tarrytown, NY, USA)/Sanofi SA (Paris, France) with their REGN727/SAR236553 antibody, now named alirocumab. ${ }^{96}$ Single-dose escalation of the antibody given intravenously $(0.3-12.0 \mathrm{mg} / \mathrm{kg})$ or subcutaneously (50-250 mg) in healthy subjects significantly reduced LDL-C levels by $28 \%-65 \%$ and $33 \%-46 \%$, respectively. Importantly, the duration of LDL-C lowering lasted up to day 64 at higher doses injected subcutaneously and up to day 106 by intravenous injection. In a multiple subcutaneous dose study in hypercholesterolemic subjects on atorvastatin treatment, alirocumab dose dependently reduced LDL-C levels by up to $65 \%$. The combination of alirocumab and atorvastatin was shown to be additive on LDL-C lowering, and the antibody was shown to be as potent with or without atorvastatin. Subsequently, a Phase II trial in subjects with LDL-C $\geq 100 \mathrm{mg} / \mathrm{dL}$ receiving stable atorvastatin therapy demonstrated that alirocumab at $150 \mathrm{mg}$ administered subcutaneously every 2 weeks resulted in dose-related LDL-C reductions of up to $72 \%$ plus reduced ApoB and lipoprotein(a) up to $56 \%$ and $29 \%$, respectively. ${ }^{97}$ In combination with atorvastatin, this dosing schedule allowed $100 \%$ of patients to achieve the treatment goals of LDL-C $<70 \mathrm{mg} / \mathrm{dL}$ and ApoB $<80 \mathrm{mg} / \mathrm{dL}$. Similar results were reported in a larger multicenter study in patients with $\mathrm{HeFH}$, including $>40 \%$ with coronary artery disease and elevated LDL-C, despite aggressive treatment with high-dose statins (atorvastatin $80 \mathrm{mg} /$ day). Alirocumab at $150 \mathrm{mg}$ every 2 weeks resulted in a decrease of LDL-C by $73 \%$ compared with a reduction of $17 \%$ with high-dose atorvastatin alone. ${ }^{98}$

In Phase I studies, Amgen's antibody (AMG145) lowered LDL-C by up to $64 \%$ (maximum single dose of
$420 \mathrm{mg}$ ) in healthy subjects and by up to $81 \%$ in hypercholesterolemic statin-treated subjects with or without $\mathrm{HeFH}$ (multiple subcutaneous dose of $140 \mathrm{mg}$ every 2 weeks). As reported for alirocumab, AMG145 also significantly reduced ApoB ( $\geq 55 \%$ ) and lipoprotein(a) (up to $50 \%$ in HeFH). ${ }^{99}$ Thereafter, AMG145 was also tested in several 12-week Phase II studies:

1. The Goal Achievement After Utilizing an AntiPCSK9 Antibody in Statin-intolerant Subjects (GAUSS) trial assessed the efficacy and tolerability of the antibody as a monotherapy in statin-intolerant hypercholesterolemic patients. ${ }^{100}$

2. The Reduction of LDL-C With PCSK9 Inhibition in Heterozygous Familial Hypercholesterolemia Disorder (RUTHERFORD) trial tested AMG145 in patients with $\mathrm{HeFH}$ with LDL-C $\geq 100 \mathrm{mg} / \mathrm{dL}$ despite statin therapy with or without ezetimibe. ${ }^{101}$

3. The Monoclonal Antibody Against PCSK9 to Reduce Elevated LDL-C in Patients Currently Not Receiving Drug Therapy for Easing Lipid Levels (MENDEL) trial tested AMG145 as a monotherapy in patients with hypercholesterolemia. ${ }^{102}$

4. The LDL-C Assessment With PCSK9 Monoclonal Antibody Inhibition Combined With Statin TherapyThrombolysis in Myocardial Infarction 57 (LAPLACETIMI 57) trial assessed the antibody in combination with a statin in patients with hypercholesterolemia. ${ }^{103}$

All four trials demonstrated that subcutaneous injections of AMG145 could reduce LDL-C by $>50 \%$ either alone or in addition to other LDL-C-lowering therapies. Overall, the antibody was well tolerated, and there were no major adverse safety signals compared with placebo.

Pfizer/Rinat RN316 (PF04950615) is a humanized monoclonal antibody that binds to PCSK9 and prevents LDLR degradation. In Phase II clinical studies, RN316 was administered intravenously in 136 hypercholesterolemic patients already on high doses of statins at $3 \mathrm{mg} / \mathrm{kg}$ or $6 \mathrm{mg} / \mathrm{kg}$ every 4 weeks for 12 weeks with an 8-week follow-up period. Preliminary data presented at the 2012 American Heart Association Scientific Sessions demonstrated, for the two doses, significant reduction in LDL-C by $\sim 46 \%$ and $56 \%$, respectively. In addition, several patients had LDL-C reduction of $>75 \%$, and some had treatment interrupted because of LDL-C levels below $25 \mathrm{mg} / \mathrm{dL}$. The effect of the antibody on LDL-C lasted for 4 weeks post-treatment without major adverse events. Phase IIb (NCT01592240) results on the subcutaneous formulation of the antibody given monthly or every 2 weeks (200-300 mg) in hypercholesterolemic 
subjects on a statin should be available soon, as the study was completed in May 2013. ${ }^{104}$

Other PCSK9 monoclonal antibodies in clinical trials include LGT209 from Novartis International AG (Basel, Switzerland)/KaloBios Pharmaceuticals, Inc (South San Francisco, CA, USA) and Roche/Genentech RG7652 (F Hoffmann-La Roche Ltd, Basel, Switzerland). LGT209, a humanized antibody derived from a mouse precursor that binds to the C-terminal residues $680-692$ of PCSK9 and poorly disrupts the PCSK 9 and LDLR interaction but inhibits LDLR degradation and restores LDL-C uptake in HepG2 cells. ${ }^{105}$ A Phase I study evaluating subcutaneous injections of LGT209 in healthy volunteers with elevated cholesterol and in hypercholesterolemic patients treated with statins was completed in May 2013, but no results have yet been released (NCT01859455). ${ }^{106}$ Roche/Genentech RG7652 (MPSK3169A), an antibody against the catalytic domain of PCSK9, is being tested in a Phase II trial by subcutaneous injections every 4 weeks for 24 weeks to patients with a high risk of cardiovascular events and elevated LDL-C levels (NCT01609140). ${ }^{107}$ The results of this study are expected by the end of 2013 .

\section{Safety and tolerability}

As opposed to drugs such as anticancer therapeutic antibodies, PCSK9 antibodies may be restricted for long-term chronic use. Results of short-term Phase I and II clinical trials using AMG145 or alirocumab indicate that the PCSK9 monoclonal antibody approach is safe and well tolerated. No evidence of drug-related serious adverse events was noted when compared with all treatment groups, including placebo. No binding or neutralizing antibodies to AMG145 have been detected to date. ${ }^{100-103}$ However, antibodies against alirocumab were detected at low titer in seven out of 56 atorvastatin-treated hypercholesterolemic patients after 8 weeks of combination treatment. ${ }^{98}$ Thus, although humanized monoclonal antibodies should reduce the risk of eliciting an immune response, it is not known whether the immunogenicity of PCSK9 antibodies will increase after several months or years of treatment. This could result in a loss of responsiveness to treatment and/or to antibody-mediated hypersensitivity reactions such as chronic systemic immunologic diseases (eg, vasculitis, arthritis, and nephritis). The answer to the issues of drug-related adverse events and immunogenicity of anti-PCSK 9 antibodies may be available only after completion of Phase III clinical trials and long-term follow-up.

Human genetic studies showed that individuals with PCSK9 LOF mutations, which result in low circulating levels of functional PCSK9 and very low LDL-C levels, are healthy and have reduced cardiovascular risks. ${ }^{20}$ Thus, it is expected that long-term PCSK9 inhibition will be a safe approach either as a monotherapy or as an add-on to statin therapy to even further reduce cardiovascular events in hypercholesterolemic patients. However, PCSK9 also induces the degradation of closely related LDLR family members ApoER2, VLDLR, ${ }^{108}$ and LRP $1{ }^{109}$ and of other transmembrane proteins such as BACE1, ${ }^{110} \mathrm{ENaC},{ }^{111}$ and CD81. ${ }^{112}$ Whereas the in vivo significance of the regulation of multiple proteins by PCSK9 remains to be demonstrated, it cannot be excluded that large population studies could reveal new phenotypes related to PCSK9 inhibition. Another important aspect that needs to be taken into account in clinical trials will be the effect of the very strong increase of LDLR stemming from the additive effect of statins (transcriptional mechanism) and PCSK9 inhibitors (post-translational mechanism). LDLR can act as a receptor for viruses such as human rhinovirus responsible for the common cold, ${ }^{113}$ vesicular stomatitis virus causing a flu-like illness in infected humans, ${ }^{114}$ and hepatitis $\mathrm{C}$ virus. ${ }^{115}$ In addition, other targets of PCSK9 such as CD81 ${ }^{116}$ (hepatitis C virus receptor), VLDLR, and LRP1 ${ }^{113,117}$ (rhinovirus receptors) have been found to act as virus receptors. Consequently, inhibition of PCSK9 activity may increase some viral infections, and the number and type of infections should be carefully monitored in Phase III clinical trials.

\section{Clinical trial updates}

Two large Phase III clinical trials are currently ongoing and recruiting volunteers. The Evaluation of Cardiovascular Outcomes After an Acute Coronary Syndrome During Treatment With Alirocumab SAR236553 (REGN727) (ODYSSEY Outcomes) trial (NCT01663402) ${ }^{118}$ will enroll $\sim 18,000$ patients worldwide who experienced an acute coronary syndrome, in order to compare the effect of alirocumab with placebo on the occurrence of cardiovascular events over a 5-year period. Patients will be on lipid-lowering therapy and dietary management but not at their LDL-C goal. The Further Cardiovascular Outcomes Research With PCSK9 Inhibition in Subjects With Elevated Risk (FOURIER) trial (NCT01764633) ${ }^{119}$ will study cardiovascular outcomes of AMG145 over $~ 5$ years in $\sim 22,500$ patients at increased risk of cardiovascular events. The major goal of these studies is to find out whether additional LDL-C reduction achieved with PCSK9 antibodies in patients on stable statin therapy with clinically evident CVD will significantly decrease major cardiovascular events better than statin therapy alone. Several other smaller Phase III trials with AMG145 and alirocumab are ongoing to collect 
long-term data on projects already initiated in Phase II trials. These studies will provide additional information about the efficacy, safety, and tolerability of anti-PCSK9 monoclonal therapy. Interestingly, a trial Global Assessment of Plaque Regression With a PCSK9 Antibody as Measured by Intravascular Ultrasound (GLAGOV; NCT01813422) ${ }^{120}$ is set to evaluate plaque regression with AMG145 in subjects with coronary artery disease on lipid-lowering therapy. Plaque size will be evaluated by intravascular ultrasound following treatment with AMG145 or placebo for 78 weeks. The therapeutic potential of neutralizing anti-PCSK9 antibodies will also be tested in the Trial Evaluating PCSK9 Antibody in Subjects With LDL Receptor Abnormalities (TESLA) (NCT01588496) ${ }^{121}$ designed to assess LDL-C reduction achieved by AMG145 in patients with homozygous FH due to LDLR mutations. Results of this trial will reveal whether increasing the level of dysfunctional LDLR, which may still have some LDL uptake activity, can be beneficial and significantly reduce LDL-C.

\section{Conclusion}

\section{Place in therapy}

In secondary prevention in high-risk patients with coronary artery disease, intensive lipid lowering with statins results in additional reduction of vascular events and mortality. ${ }^{122,123}$ Indeed, it is estimated that for every $1 \mathrm{mmol} / \mathrm{L}(39 \mathrm{mg} / \mathrm{dL})$ reduction in LDL-C, the risk of annual rate of major vascular events is decreased by $21 \% .{ }^{124}$ However, the clinical benefits of high-dose statin therapy may not solely depend on lowering LDL-C level. Statins also have anti-inflammatory effects and reduce the inflammatory biomarker high-sensitivity C-reactive protein, which is associated with better cardiovascular outcomes. ${ }^{125}$ Additionally, achieving lower concentration of both LDL-C and high-sensitivity C-reactive protein is predictive of better outcomes. ${ }^{125}$ Yet it is not feasible to establish whether the clinical benefits of statins are due to LDL-C reduction alone, to inflammation inhibition, or to a combination of both activities. ${ }^{126}$

It is expected that aggressive LDL-C reduction alone, achieved through PCSK9 inhibition, will be atheroprotective. This is exemplified by genetic studies in humans ${ }^{20,77,78,127}$ and in mouse ${ }^{128,129}$ and minipig models ${ }^{130}$ showing that development of clinical signs of hypercholesterolemia and atherosclerotic lesions are directly associated with PCSK9 expression and LDL-C levels. Large Phase III clinical trials should establish whether anti-PCSK9 antibodies, which could help more than $80 \%$ of hypercholesterolemic patients to achieve an LDL-C concentration lower than or down to optimal target level ( $\sim 70 \mathrm{mg} / \mathrm{dL})$, have potential for further reduction of the occurrence of major vascular events in humans better than that achieved through HMG-CoA reductase inhibitors.

\section{Acknowledgment}

This work was supported by grants from the Canadian Institutes of Health Research (Institute of Nutrition, Metabolism, and Diabetes), Fonds de recherche du Québec-Santé, the Heart and Stroke Foundation of Canada, and the Montreal Heart Institute Foundation.

\section{Disclosure}

The authors of this publication have no conflicts of interest in this work.

\section{References}

1. Mackay J, Mensah GA. The atlas of heart disease and stroke. Geneva: World Health Organization; 2004.

2. Heidenreich PA, Trogdon JG, Khavjou OA, et al. Forecasting the future of cardiovascular disease in the United States: a policy statement from the American Heart Association. Circulation. 2011;123(8):933-944.

3. Kannel WB, Dawber TR, Kagan A, Revotskie N, Stokes J 3rd. Factors of risk in the development of coronary heart disease - six year follow-up experience. The Framingham Study. Ann Intern Med. 1961;55: 33-50.

4. Müller C. Xanthoma, hypercholesterolemia, angina pectoris. Acta Med Scand Suppl. 1938;(89):75-84.

5. Yusuf S, Hawken S, Ounpuu S, et al. Effect of potentially modifiable risk factors associated with myocardial infarction in 52 countries (the INTERHEART study): case-control study. Lancet. 2004;364(9438): 937-952.

6. Lusis AJ. Atherosclerosis. Nature. 2000;407(6801):233-241.

7. Brown MS, Goldstein JL. A receptor-mediated pathway for cholesterol homeostasis. Science. 1986;232(4746):34-47.

8. Marduel M, Ouguerram K, Serre V, et al. Description of a large family with autosomal dominant hypercholesterolemia associated with the APOE p.Leu167del mutation. Hum Mutat. 2013;34(1):83-87.

9. Rader DJ, Cohen J, Hobbs HH. Monogenic hypercholesterolemia: new insights in pathogenesis and treatment. J Clin Invest. 2003;111(12): $1795-1803$

10. Seidah NG, Benjannet S, Wickham L, et al. The secretory proprotein convertase neural apoptosis-regulated convertase 1 (NARC-1): liver regeneration and neuronal differentiation. Proc Natl Acad Sci U S A. 2003;100(3):928-933.

11. Abifadel M, Varret M, Rabès JP, et al. Mutations in PCSK9 cause autosomal dominant hypercholesterolemia. Nat Genet. 2003;34(2): $154-156$.

12. Abifadel M, Guerin M, Benjannet S, et al. Identification and characterization of new gain-of-function mutations in the PCSK9 gene responsible for autosomal dominant hypercholesterolemia. Atherosclerosis. 2012;223(2):394-400.

13. Maxwell KN, Breslow JL. Adenoviral-mediated expression of Pcsk9 in mice results in a low-density lipoprotein receptor knockout phenotype. Proc Natl Acad Sci U SA. 2004;101(18):7100-7105.

14. Benjannet S, Rhainds D, Essalmani R, et al. NARC-1/PCSK9 and its natural mutants: zymogen cleavage and effects on the low density lipoprotein (LDL) receptor and LDL cholesterol. J Biol Chem. 2004; 279(47):48865-48875.

15. Park SW, Moon YA, Horton JD. Post-transcriptional regulation of low density lipoprotein receptor protein by proprotein convertase subtilisin/kexin type 9a in mouse liver. J Bio Chem. 2004;279(48): 50630-50638. 
16. Cohen J, Pertsemlidis A, Kotowski IK, Graham R, Garcia CK, Hobbs HH. Low LDL cholesterol in individuals of African descent resulting from frequent nonsense mutations in PCSK9. Nat Genet. 2005;37(2):161-165.

17. Berge KE, Ose L, Leren TP. Missense mutations in the PCSK9 gene are associated with hypocholesterolemia and possibly increased response to statin therapy. Arterioscler Thromb Vasc Biol. 2006;26(5): 1094-1100.

18. Hooper AJ, Marais AD, Tanyanyiwa DM, Burnett JR. The C679X mutation in PCSK9 is present and lowers blood cholesterol in a Southern African population. Atherosclerosis. 2007;193(2):445-448.

19. Rashid S, Curtis DE, Garuti R, et al. Decreased plasma cholesterol and hypersensitivity to statins in mice lacking Pcsk9. Proc Natl Acad Sci U SA. 2005;102(15):5374-5379.

20. Cohen JC, Boerwinkle E, Mosley TH Jr, Hobbs HH. Sequence variations in PCSK9, low LDL, and protection against coronary heart disease. N Engl J Med. 2006;354(12):1264-1272.

21. Leigh SE, Foster AH, Whittall RA, Hubbart CS, Humphries SE. Update and analysis of the University College London low density lipoprotein receptor familial hypercholesterolemia database. Ann Hum Genet. 2008;72(Pt 4):485-498.

22. Leigh SE, Leren TP, Humphries SE. Commentary PCSK9 variants: a new database. Atherosclerosis. 2009;203(1):32-33.

23. Abifadel M, Rabès JP, Devillers M, et al. Mutations and polymorphisms in the proprotein convertase subtilisin kexin 9 (PCSK9) gene in cholesterol metabolism and disease. Hum Mutat. 2009;30(4):520-529.

24. Horton JD, Shah NA, Warrington JA, et al. Combined analysis of oligonucleotide microarray data from transgenic and knockout mice identifies direct SREBP target genes. Proc Natl Acad Sci U S A. 2003;100(21):12027-12032.

25. Maxwell KN, Soccio RE, Duncan EM, Sehayek E, Breslow JL. Novel putative SREBP and LXR target genes identified by microarray analysis in liver of cholesterol-fed mice. J Lipid Res. 2003;44(11):2109-2119.

26. Wenner Moyer M. The search beyond statins. Nat Med. 2010;16(2): $150-153$

27. Dubuc G, Chamberland A, Wassef H, et al. Statins upregulate PCSK9, the gene encoding the proprotein convertase neural apoptosis-regulated convertase-1 implicated in familial hypercholesterolemia. Arterioscler Thromb Vasc Biol. 2004;24(8):1454-1459.

28. Jung D, Kullak-Ublick GA. Hepatocyte nuclear factor 1 alpha: a key mediator of the effect of bile acids on gene expression. Hepatology. 2003;37(3):622-631.

29. Li H, Dong B, Park SW, Lee HS, Chen W, Liu J. Hepatocyte nuclear factor 1alpha plays a critical role in PCSK9 gene transcription and regulation by the natural hypocholesterolemic compound berberine. J Biol Chem. 2009;284(42):28885-28895.

30. Kong W, Wei J, Abidi P, et al. Berberine is a novel cholesterol-lowering drug working through a unique mechanism distinct from statins. Nat Med. 2004;10(12):1344-1351.

31. Cameron J, Ranheim T, Kulseth MA, Leren TP, Berge KE. Berberine decreases PCSK9 expression in HepG2 cells. Atherosclerosis. 2008;201(2):266-273.

32. Abidi P, Zhou Y, Jiang JD, Liu J. Extracellular signal-regulated kinase-dependent stabilization of hepatic low-density lipoprotein receptor mRNA by herbal medicine berberine. Arterioscler Thromb Vasc Biol. 2005;25(10):2170-2176.

33. Cunningham D, Danley DE, Geoghegan KF, et al. Structural and biophysical studies of PCSK9 and its mutants linked to familial hypercholesterolemia. Nat Struct Mol Biol. 2007;14(5):413-419.

34. Naureckiene S, Ma L, Sreekumar K, et al. Functional characterization of Narc 1, a novel proteinase related to proteinase K. Arch Biochem Biophys. 2003;420(1):55-67.

35. Seidah NG, Mayer G, Zaid A, et al. The activation and physiological functions of the proprotein convertases. Int J Biochem Cell Biol. 2008;40(6-7):1111-1125.

36. Seidah NG, Prat A. The biology and therapeutic targeting of the proprotein convertases. Nat Rev Drug Discov. 2012;11(5):367-383.
37. Zhao Z, Tuakli-Wosornu Y, Lagace TA, et al. Molecular characterization of loss-of-function mutations in PCSK9 and identification of a compound heterozygote. Am J Hum Genet. 2006;79(3):514-523.

38. Mayne J, Dewpura T, Raymond A, et al. Novel loss-of-function PCSK9 variant is associated with low plasma LDL cholesterol in a FrenchCanadian family and with impaired processing and secretion in cell culture. Clin Chem. 2011;57(10):1415-1423.

39. Cariou B, Ouguerram K, ZaïrY, et al. PCSK9 dominant negative mutant results in increased LDL catabolic rate and familial hypobetalipoproteinemia. Arterioscler Thromb Vasc Biol. 2009;29(12): 2191-2197.

40. Mancias JD, Goldberg J. Structural basis of cargo membrane protein discrimination by the human COPII coat machinery. EMBO J. 2008;27(21):2918-2928.

41. Chen XW, Wang H, Bajaj K, et al. SEC24A deficiency lowers plasma cholesterol through reduced PCSK9 secretion. eLife. 2013;2: e00444.

42. McNutt MC, Lagace TA, Horton JD. Catalytic activity is not required for secreted PCSK9 to reduce low density lipoprotein receptors in HepG2 cells. J Biol Chem. 2007;282(29):20799-20803.

43. Thomas G. Furin at the cutting edge: from protein traffic to embryogenesis and disease. Nat Rev Mol Cell Biol. 2002;3(10):753-766.

44. Mayer G, Boileau G, Bendayan M. The proprotein convertase furin colocalizes with caveolin-1 in the Golgi apparatus and endosomes of hepatocytes. Cell Tissue Res. 2004;316(1):55-63.

45. Mayer G, Boileau G, Bendayan M. Sorting of furin in polarized epithelial and endothelial cells: expression beyond the Golgi apparatus. J Histochem Cytochem. 2004;52(5):567-579.

46. Boucher E, Mayer G, Londono I, Bendayan M. Expression and localization of MT1-MMP and furin in the glomerular wall of short- and long-term diabetic rats. Kidney Int. 2006;69(9):1570-1577.

47. Benjannet S, Rhainds D, Hamelin J, Nassoury N, Seidah NG. The proprotein convertase (PC) PCSK9 is inactivated by furin and/or PC5/6A: functional consequences of natural mutations and post-translational modifications. J Biol Chem. 2006;281(41):30561-30572.

48. Essalmani R, Susan-Resiga D, Chamberland A, et al. In vivo evidence that furin from hepatocytes inactivates PCSK9. J Biol Chem. 2011;286(6):4257-4263.

49. Mayer G, Hamelin J, Asselin MC, et al. The regulated cell surface zymogen activation of the proprotein convertase PC5A directs the processing of its secretory substrates. J Biol Chem. 2008;283(4):2373-2384.

50. Lipari MT, Li W, Moran P, et al. Furin-cleaved proprotein convertase subtilisin/kexin type 9 (PCSK9) is active and modulates low density lipoprotein receptor and serum cholesterol levels. J Biol Chem. 2012; 287(52):43482-43491.

51. Allard D, Amsellem S, Abifadel M, et al. Novel mutations of the PCSK9 gene cause variable phenotype of autosomal dominant hypercholesterolemia. Hum Mutat. 2005;26(5):497.

52. Abdiche Y, Riggers J, Gomes B, et al, inventors; Pfizer, Rinat Neuroscience Corp, assignee. PCSK9 antagonists. United States patent US 20100068199 A1. March 18, 2010.

53. Maxwell KN, Fisher EA, Breslow JL. Overexpression of PCSK9 accelerates the degradation of the LDLR in a post-endoplasmic reticulum compartment. Proc Natl Acad Sci U S A. 2005;102(6): 2069-2074.

54. Zhang DW, Lagace TA, Garuti R, et al. Binding of proprotein convertase subtilisin/kexin type 9 to epidermal growth factor-like repeat A of low density lipoprotein receptor decreases receptor recycling and increases degradation. J Biol Chem. 2007;282(25):18602-18612.

55. Kwon HJ, Lagace TA, McNutt MC, Horton JD, Deisenhofer J. Molecular basis for LDL receptor recognition by PCSK9. Proc Natl Acad Sci U SA. 2008;105(6):1820-1825.

56. Nassoury N, Blasiole DA, Tebon Oler A, et al. The cellular trafficking of the secretory proprotein convertase PCSK9 and its dependence on the LDLR. Traffic. 2007;8(6):718-732.

57. Wang Y, Huang Y, Hobbs HH, Cohen JC. Molecular characterization of proprotein convertase subtilisin/kexin type 9-mediated degradation of the LDLR. J Lipid Res. 2012;53(9):1932-1943. 
58. Lagace TA, Curtis DE, Garuti R, et al. Secreted PCSK9 decreases the number of LDL receptors in hepatocytes and in livers of parabiotic mice. J Clin Invest. 2006;116(11):2995-3005.

59. Malby S, Pickering R, Saha S, Smallridge R, Linse S, Downing AK. The first epidermal growth factor-like domain of the low-density lipoprotein receptor contains a noncanonical calcium binding site. Biochemistry (Mosc). 2001;40(8):2555-2563.

60. Yamamoto T, Lu C, Ryan RO. A two-step binding model of PCSK9 interaction with the low density lipoprotein receptor. J Biol Chem. 2011;286(7):5464-5470.

61. Zhang DW, Garuti R, Tang WJ, Cohen JC, Hobbs HH. Structural requirements for PCSK9-mediated degradation of the low-density lipoprotein receptor. Proc Natl Acad Sci U S A. 2008;105(35): 13045-13050.

62. Poirier S, Mayer G, Poupon V, et al. Dissection of the endogenous cellular pathways of PCSK9-induced low density lipoprotein receptor degradation: evidence for an intracellular route. $J$ Biol Chem. 2009;284(42):28856-28864.

63. Benjannet S, Saavedra YG, Hamelin J, et al. Effects of the prosegment and $\mathrm{pH}$ on the activity of PCSK9: evidence for additional processing events. J Biol Chem. 2010;285(52):40965-40978.

64. Holla ØL, Laerdahl JK, Strøm TB, et al. Removal of acidic residues of the prodomain of PCSK9 increases its activity towards the LDL receptor. Biochem Biophys Res Commun. 2011;406(2):234-238.

65. Sun H, Samarghandi A, Zhang N, Yao Z, Xiong M, Teng BB. Proprotein convertase subtilisin/kexin type 9 interacts with apolipoprotein B and prevents its intracellular degradation, irrespective of the low-density lipoprotein receptor. Arterioscler Thromb Vasc Biol. 2012;32(7): $1585-1595$.

66. Fisher TS, Lo Surdo P, Pandit S, et al. Effects of $\mathrm{pH}$ and low density lipoprotein (LDL) on PCSK9-dependent LDL receptor regulation. J Biol Chem. 2007;282(28):20502-20512.

67. Kosenko T, Golder M, Leblond G, Weng W, Lagace TA. Low density lipoprotein binds to proprotein convertase subtilisin/kexin type-9 (PCSK9) in human plasma and inhibits PCSK9-mediated low density lipoprotein receptor degradation. J Biol Chem. 2013;288(12): 8279-8288.

68. Lo Surdo P, Bottomley MJ, Calzetta A, et al. Mechanistic implications for LDL receptor degradation from the PCSK9/LDLR structure at neutral pH. EMBO Reports. 2011;12(12):1300-1305.

69. Bottomley MJ, Cirillo A, Orsatti L, et al. Structural and biochemical characterization of the wild type PCSK9-EGF(AB) complex and natural familial hypercholesterolemia mutants. J Biol Chem. 2009;284(2):1313-1323.

70. Tveten K, Holla ØL, Cameron J, et al. Interaction between the ligandbinding domain of the LDL receptor and the C-terminal domain of PCSK9 is required for PCSK9 to remain bound to the LDL receptor during endosomal acidification. Hum Mol Genet. 2012;21(6): $1402-1409$.

71. Du F, Hui Y, Zhang M, Linton MF, Fazio S, Fan D. Novel domain interaction regulates secretion of proprotein convertase subtilisin/ kexin type 9 (PCSK9) protein. J Biol Chem. 2011;286(50): 43054-43061.

72. Ni YG, Condra JH, Orsatti L, et al. A proprotein convertase subtilisinlike/kexin type 9 (PCSK9) C-terminal domain antibody antigen-binding fragment inhibits PCSK9 internalization and restores low density lipoprotein uptake. J Biol Chem. 2010;285(17):12882-12891.

73. Strøm TB, Holla ØL, Tveten K, Cameron J, Berge KE, Leren TP. Disrupted recycling of the low density lipoprotein receptor by PCSK9 is not mediated by residues of the cytoplasmic domain. Mol Genet Metab. 2010;101(1):76-80.

74. Mayer G, Poirier S, Seidah NG. Annexin A2 is a C-terminal PCSK9-binding protein that regulates endogenous low density lipoprotein receptor levels. J Biol Chem. 2008;283(46):31791-31801.

75. Seidah NG, Poirier S, Denis M, et al. Annexin A2 is a natural extrahepatic inhibitor of the PCSK9-induced LDL receptor degradation. PLoS One. 2012;7(7):e41865.
76. Timms KM, Wagner S, Samuels ME, et al. A mutation in PCSK9 causing autosomal-dominant hypercholesterolemia in a Utah pedigree. Hum Genet. 2004;114(4):349-353.

77. Leren TP. Mutations in the PCSK9 gene in Norwegian subjects with autosomal dominant hypercholesterolemia. Clin Genet. 2004;65(5): 419-422.

78. Naoumova RP, Tosi I, Patel D, et al. Severe hypercholesterolemia in four British families with the D374Y mutation in the PCSK9 gene: long-term follow-up and treatment response. Arterioscler Thromb Vasc Biol. 2005;25(12):2654-2660.

79. McNutt MC, Kwon HJ, Chen C, Chen JR, Horton JD, Lagace TA. Antagonism of secreted PCSK9 increases low density lipoprotein receptor expression in HepG2 cells. J Biol Chem. 2009;284(16): 10561-10570.

80. Shan L, Pang L, Zhang R, Murgolo NJ, Lan H, Hedrick JA. PCSK9 binds to multiple receptors and can be functionally inhibited by an EGF-A peptide. Biochem Biophys Res Commun. 2008;375(1):69-73.

81. Liu M, Wu G, Baysarowich J, et al. PCSK9 is not involved in the degradation of LDL receptors and BACE1 in the adult mouse brain. $J$ Lipid Res. 2010;51(9):2611-2618.

82. Zhang Y, Zhou L, Kong-Beltran M, et al. Calcium-independent inhibition of PCSK9 by affinity-improved variants of the LDL receptor EGF(A) domain. $J$ Mol Biol. 2012;422(5):685-696.

83. O'Keefe JH Jr, Cordain L, Harris WH, Moe RM, Vogel R. Optimal low-density lipoprotein is 50 to $70 \mathrm{mg} / \mathrm{dL}$ : lower is better and physiologically normal. J Am Coll Cardiol. 2004;43(11):2142-2146.

84. Baigent C, Blackwell L, Emberson J, et al. Efficacy and safety of more intensive lowering of LDL cholesterol: a meta-analysis of data from 170,000 participants in 26 randomised trials. Lancet. 2010;376(9753):1670-1681.

85. Kapur NK, Musunuru K. Clinical efficacy and safety of statins in managing cardiovascular risk. Vasc Health Risk Manag. 2008;4(2): 341-353.

86. Hou R, Goldberg AC. Lowering low-density lipoprotein cholesterol: statins, ezetimibe, bile acid sequestrants, and combinations: comparative efficacy and safety. Endocrinol Metab Clin North Am. 2009;38(1): 79-97.

87. Bruckert E, Hayem G, Dejager S, Yau C, Begaud B. Mild to moderate muscular symptoms with high-dosage statin therapy in hyperlipidemic patients: the PRIMO study. Cardiovasc Drugs Ther. 2005;19(6): 403-414.

88. Duff CJ, Scott MJ, Kirby IT, Hutchinson SE, Martin SL, Hooper NM. Antibody-mediated disruption of the interaction between PCSK9 and the low-density lipoprotein receptor. Biochem J. 2009;419(3):577-584.

89. Chan JC, Piper DE, Cao Q, et al. A proprotein convertase subtilisin/ kexin type 9 neutralizing antibody reduces serum cholesterol in mice and nonhuman primates. Proc Natl Acad Sci U S A. 2009;106(24): 9820-9825.

90. Ni YG, Di Marco S, Condra JH, et al. A PCSK9-binding antibody that structurally mimics the EGF(A) domain of LDL-receptor reduces LDL cholesterol in vivo. J Lipid Res. 2011;52(1):78-86.

91. Condra J, Cubbon R, Hammond H, et al, inventors; Merck, assignee. 1D05 PCSK9 antagonists. United States patent US 20120301461A1. November 12, 2012.

92. Zhang L, McCabe T, Condra JH, et al. An anti-PCSK9 antibody reduces LDL-cholesterol on top of a statin and suppresses hepatocyte SREBPregulated genes. Int J Biol Sci. 2012;8(3):310-327.

93. Liang H, Chaparro-Riggers J, Strop P, et al. Proprotein convertase substilisin/kexin type 9 antagonism reduces low-density lipoprotein cholesterol in statin-treated hypercholesterolemic nonhuman primates. J Pharmacol Exp Ther. 2012;340(2):228-236.

94. Chaparro-Riggers J, Liang H, DeVay RM, et al. Increasing serum halflife and extending cholesterol lowering in vivo by engineering antibody with $\mathrm{pH}$-sensitive binding to PCSK9. J Biol Chem. 2012;287(14): 11090-11097.

95. Davies J, Darling R, Allan B, Inventors; Eli Lilly and Company, assignee. Antibodies to PCSK9 and uses thereof US patent US20130071405A1. March 21, 2013. 
96. Stein EA, Mellis S, Yancopoulos GD, et al. Effect of a monoclonal antibody to PCSK9 on LDL cholesterol. N Engl J Med. 2012;366(12): $1108-1118$.

97. McKenney JM, Koren MJ, Kereiakes DJ, Hanotin C, Ferrand AC, Stein EA. Safety and efficacy of a monoclonal antibody to proprotein convertase subtilisin/kexin type 9 serine protease, SAR236553/ REGN727, in patients with primary hypercholesterolemia receiving ongoing stable atorvastatin therapy. J Am Coll Cardiol. 2012;59(25): 2344-2353.

98. Roth EM, McKenney JM, Hanotin C, Asset G, Stein EA. Atorvastatin with or without an antibody to PCSK 9 in primary hypercholesterolemia. N Engl J Med. 2012;367(20):1891-1900.

99. Dias CS, Shaywitz AJ, Wasserman SM, et al. Effects of AMG 145 on low-density lipoprotein cholesterol levels: results from 2 randomized, double-blind, placebo-controlled, ascending-dose phase 1 studies in healthy volunteers and hypercholesterolemic subjects on statins. J Am Coll Cardiol. 2012;60(19):1888-1898.

100. Sullivan D, Olsson AG, Scott R, et al. Effect of a monoclonal antibody to PCSK9 on low-density lipoprotein cholesterol levels in statinintolerant patients: the GAUSS randomized trial. JAMA. 2012;308(23): 2497-2506.

101. Raal F, Scott R, Somaratne R, et al. Low-density lipoprotein cholesterollowering effects of AMG 145, a monoclonal antibody to proprotein convertase subtilisin/kexin type 9 serine protease in patients with heterozygous familial hypercholesterolemia: the Reduction of LDL-C With PCSK9 Inhibition in Heterozygous Familial Hypercholesterolemia Disorder (RUTHERFORD) randomized trial. Circulation. 2012;126(20):2408-2417.

102. Koren MJ, Scott R, Kim JB, et al. Efficacy, safety, and tolerability of a monoclonal antibody to proprotein convertase subtilisin/kexin type 9 as monotherapy in patients with hypercholesterolaemia (MENDEL): a randomised, double-blind, placebo-controlled, phase 2 study. Lancet. 2012;380(9858):1995-2006.

103. Giugliano RP, Desai NR, Kohli P, et al. Efficacy, safety, and tolerability of a monoclonal antibody to proprotein convertase subtilisin/ kexin type 9 in combination with a statin in patients with hypercholesterolaemia (LAPLACE-TIMI 57): a randomised, placebocontrolled, dose-ranging, phase 2 study. Lancet. 2012;380(9858): 2007-2017.

104. Pfizer. Monthly and twice monthly subcutaneous dosing of PF-04950615 (RN316) in hypercholesterolemic subjects on a statin. Available from: http:/clinicaltrials.gov/ct2/show/NCT01592240. http:/clinicaltrials. gov/ct2/show/NCT01592240. NLM identifier: NCT01592240. Accessed September 12, 2013.

105. Rue S, Cohen S, Li J, Yowe D, inventors; IRM LLC, Novartis AG, assignee. PCSK9 antagonists. United States patent US 20110142849A1. June 16, 2011.

106. Novartis Pharmaceuticals. Safety, pharmacokinetics and pharmacodynamics of LGT209 in healthy volunteers with elevated cholesterol and in hypercholesterolemic patients treated with statins. Available from: http://www.clinicaltrials.gov/ct2/show/NCT00265317. http://clinicaltrials.gov/ct2/show/NCT01859455. NLM identifier: NCT01859455. Accessed September 12, 2013.

107. Genentech. A phase II study of the safety and efficacy of MPSK3169A in patients with coronary heart disease or high risk of coronary heart disease. Available from: http://clinicaltrials.gov/ct2/show/NCT01609140. http:/clinicaltrials.gov/ct2/show/NCT01609140. NLM identifier: NCT01609140. Accessed September 12, 2013.

108. Poirier S, Mayer G, Benjannet S, et al. The proprotein convertase PCSK9 induces the degradation of low density lipoprotein receptor (LDLR) and its closest family members VLDLR and ApoER2. J Biol Chem. 2008;283(4):2363-2372.

109. Canuel M, Sun X, Asselin MC, Paramithiotis E, Prat A, Seidah NG. Proprotein convertase subtilisin/kexin type 9 (PCSK9) can mediate degradation of the low density lipoprotein receptor-related protein 1 (LRP-1). PLoS One. 2013;8(5):e64145.
110. Jonas MC, Costantini C, Puglielli L. PCSK9 is required for the disposal of non-acetylated intermediates of the nascent membrane protein BACE1. EMBO Reports. 2008;9(9):916-922.

111. Sharotri V, Collier DM, Olson DR, Zhou R, Snyder PM. Regulation of epithelial sodium channel trafficking by proprotein convertase subtilisin/ kexin type 9 (PCSK9). J Biol Chem. 2012;287(23):19266-19274.

112. Labonté P, Begley S, Guévin C, et al. PCSK9 impedes hepatitis C virus infection in vitro and modulates liver CD81 expression. Hepatology. 2009;50(1):17-24.

113. Hofer F, Gruenberger M, Kowalski H, et al. Members of the low density lipoprotein receptor family mediate cell entry of a minor-group common cold virus. Proc Natl Acad Sci U S A. 1994;91(5):1839-1842.

114. Finkelshtein D, Werman A, Novick D, Barak S, Rubinstein M. LDL receptor and its family members serve as the cellular receptors for vesicular stomatitis virus. Proc Natl Acad Sci U SA. 2013;110(18): 7306-7311.

115. Agnello V, Abel G, Elfahal M, Knight GB, Zhang QX. Hepatitis C virus and other flaviviridae viruses enter cells via low density lipoprotein receptor. Proc Natl Acad Sci U S A. 1999;96(22):12766-12771.

116. Pileri P, Uematsu Y, Campagnoli S, et al. Binding of hepatitis $C$ virus to CD81. Science. 1998;282(5390):938-941.

117. Marlovits TC, Abrahamsberg C, Blaas D. Very-low-density lipoprotein receptor fragment shed from HeLa cells inhibits human rhinovirus infection. J Virol. 1998;72(12):10246-10250.

118. Sanofi. Evaluation of cardiovascular outcomes after an acute coronary syndrome during treatment with alirocumab SAR236553 (REGN727) (ODYSSEY outcomes). Available from: http://clinicaltrials.gov/ct2/ show/NCT01663402. http://clinicaltrials.gov/ct2/show/NCT01663402. NLM identifier: NCT01663402. Accessed September 12, 2013.

119. Amgen. Further cardiovascular outcomes research with PCSK9 inhibition in subjects with elevated risk (FOURIER). Available from: http:// clinicaltrials.gov/ct2/show/NCT01764633. http://clinicaltrials.gov/ ct2/show/NCT01764633. NLM identifier: NCT01764633. Accessed September 12, 2013.

120. Amgen. GLobal Assessment of plaque reGression with a PCSK9 antibOdy as measured by intraVascular ultrasound (GLAGOV). Available from: http://clinicaltrials.gov/ct2/show/NCT01813422. http://clinicaltrials.gov/ct2/show/NCT01813422. NLM identifier: NCT01813422. Accessed September 12, 2013.

121. Amgen. Trial evaluating PCSK9 antibody in subjects with LDL receptor abnormalities (TESLA). Available from: http://clinicaltrials.gov/ct2/show/NCT01588496. http://clinicaltrials.gov/ct2/ show/NCT01588496. NLM identifier: NCT01588496. Accessed September 12, 2013.

122. Cannon $\mathrm{CP}$, Braunwald $\mathrm{E}, \mathrm{McCabe} \mathrm{CH}$, et al. Intensive versus moderate lipid lowering with statins after acute coronary syndromes. $N$ Engl J Med. 2004;350(15):1495-1504.

123. Law MR, Wald NJ, Rudnicka AR. Quantifying effect of statins on low density lipoprotein cholesterol, ischaemic heart disease, and stroke: systematic review and meta-analysis. BMJ. 2003;326(7404):1423.

124. Mihaylova B, Emberson J, Blackwell L, et al. The effects of lowering LDL cholesterol with statin therapy in people at low risk of vascular disease: meta-analysis of individual data from 27 randomised trials. Lancet. 2012;380(9841):581-590.

125. Ridker PM, Danielson E, Fonseca FA, et al. Reduction in C-reactive protein and LDL cholesterol and cardiovascular event rates after initiation of rosuvastatin: a prospective study of the JUPITER trial. Lancet. 2009;373(9670):1175-1182.

126. Ridker PM. Moving beyond JUPITER: will inhibiting inflammation reduce vascular event rates? Curr Atheroscler Rep. 2013;15(1):295.

127. Sun XM, Eden ER, Tosi I, et al. Evidence for effect of mutant PCSK9 on apolipoprotein B secretion as the cause of unusually severe dominant hypercholesterolaemia. Hum Mol Genet. 2005;14(9):1161-1169.

128. Herbert B, Patel D, Waddington SN, et al. Increased secretion of lipoproteins in transgenic mice expressing human D374YPCSK9 under physiological genetic control. Arterioscler Thromb Vasc Biol. 2010;30(7):1333-1339. 
129. Denis M, Marcinkiewicz J, Zaid A, et al. Gene inactivation of proprotein convertase subtilisin/kexin type 9 reduces atherosclerosis in mice. Circulation. 2012;125(7):894-901.

130. Al-Mashhadi RH, Sørensen CB, Kragh PM, et al. Familial hypercholesterolemia and atherosclerosis in cloned minipigs created by DNA transposition of a human PCSK9 gain-of-function mutant. Sci Transl Med. 2013;5(166):166ra161.
131. Rudenko G, Henry L, Henderson K, et al. Structure of the LDL receptor extracellular domain at endosomal $\mathrm{pH}$. Science. December 20, 2002;298(5602):2353-2358.

\section{Publish your work in this journal}

Drug Design, Development and Therapy is an international, peerreviewed open-access journal that spans the spectrum of drug design and development through to clinical applications. Clinical outcomes, patient safety, and programs for the development and effective, safe, and sustained use of medicines are a feature of the journal, which has also been accepted for indexing on PubMed Central. The manuscript management system is completely online and includes a very quick and fair peer-review system, which is all easy to use. Visit http://www.dovepress.com/testimonials.php to read real quotes from published authors.

Submit your manuscript here: http://www.dovepress.com/drug-design-development-and-therapy-journal 